\title{
LAS ELECCIONES MUNICIPALES Y LA RECOMPOSICIÓN POLÍTICA EN CHILE: DESAFÍOS Y PERSPECTIVAS (2008-2010)
}

\author{
Gustavo Javier Castro Silva* \\ Carlos Federico Domínguez Ávila**
}

\begin{abstract}
RESUMEN: El propósito del presente artículo es evaluar los antecedentes, los resultados y las implicaciones políticas derivadas de las elecciones municipales chilenas realizadas el día 26 de octubre de 2008. En la opinión de los autores, esta elección implicó el inicio de una recomposición de las fuerzas político-electorales chilenas, resultando en la primera victoria significativa de la coalición opositora de centro-derecha y, concomitantemente, una significativa derrota electoral en el ámbito nacional, de la Concertación, que gobierna el país desde 1990. Aun reconociendo que esta elección tiene fundamentalmente impacto en la esfera local o municipal, sus consecuencias en el plano nacional adquieren relevancia, dado que en 2009 serán realizadas las elecciones presidenciales que llevarán un nuevo gobernante a La Moneda.
\end{abstract}

Palabras Clave: Chile, Elecciones municipales, Sociología política, Consolidación democrática, Sistema electoral, Coaliciones políticas.

ABSTRACT: This article is an evaluation of the origins, results and the political implications of the Chilean election of October 26, 2008. It is the authors' opinion that this election allowed for a rearrangement of the Chilean politicalelectoral scenario. The end result of these elections was the first significant victory of the center-right political factions and marks the first significant national defeat of the Concertación, which has been in power since 1990. Although the authors acknowledge that this election had more impact the local (municipal) level, its consequences at the national level become much more significant because of the proximity of the forthcoming presidential election of 2009.

Key words: Chile, Local elections, Political sociology, Democratic transitions, Electoral system, Political coalitions.

*Universidad de Brasilia (gjcs62@terra.com.br).

${ }^{* *}$ Centro Universitario Unieuro (cdominguez_unieuro@yahoo.com.br). 


\section{INTRODUCCIÓN}

El propósito del presente artículo es evaluar los antecedentes, los resultados y las implicaciones políticas derivadas de las elecciones municipales chilenas realizadas el día 26 de octubre de 2008. En tal sentido, el trabajo está organizado en torno de cuatro subtítulos donde se exploran las principales características del sistema electoral vigente en el país, las fuerzas políticas que participaron en los comicios municipales, una evaluación de los resultados y las implicaciones que - salvo mejor interpretación - pueden influir en el futuro político-partidario del país, sobre todo al comprobar que las próximas elecciones presidenciales y parlamentarias chilenas están programadas para diciembre de 2009.

En nuestra opinión — que acompañamos in loco el desarrollo de los comicios - esta elección implicó el inicio de una recomposición de las fuerzas político-electorales chilenas. Obsérvese, por ejemplo, que por primera vez desde el retorno al régimen democrático las fuerzas políticas de centro-derecha, ligadas a la denominada Alianza por Chile, consiguieron una votación superior a la de los candidatos de la coalición de la Concertación de Partidos por la Democracia. En otras palabras se trató de la primera derrota significativa en el ámbito nacional de la coalición que gobierna el país desde 1990; lo que obviamente es altamente significativo, revelador y sugestivo. ${ }^{1}$

1 La Concertación de Partidos por la Democracia fue creada en octubre de 1988. Esencialmente se trata de los partidos opositores moderados al régimen militar y que participaron en la campaña contra las pretensiones continuistas del general Pinochet. Los partidos que forman parte de la Concertación son el Partido Demócrata Cristiano, el Partido Socialista, el Partido por la Democracia y el Partido Radical Socialdemócrata. Los principales líderes de la Concertación son Patricio Aylwin (presidente de la República entre 1990 y 1994), Eduardo Frei (presidente de la República entre 1994 y 2000), Ricardo Lagos (presidente de la República entre 2000 y 2006) y Michelle Bachelet (presidenta de la República entre 2006 y 2010). En los Anexos 1 y 2 los partidos de esta coalición aparecen subdivididos en Concertación Democrática y Concertación Progresista. Entretanto, la Alianza por Chile fue oficialmente instituida en 2000. La misma es integrada por dos partidos políticos principales: Renovación Nacional y la Unión Democrática Independiente. Los principales dirigentes de esta coalición son: Sebastián Piñeira, Joaquín Lavín y Pablo Longueira. 
Al mismo tiempo, conviene reconocer algunos presupuestos teóricometodológicos que orientan y recorren el artículo. Así, se entiende que el término sistema electoral se refiere al conjunto de acciones que posibilitan la conversión de votos en puestos de mando. Igualmente, se acepta que en la elaboración y en la reforma de los sistemas electorales siempre están presentes tres principios. El primero de ellos es el de la representatividad, el cual requiere caracterizar la diversidad social y los grupos con mayor peso político, lo que debe reflejarse en la cuota proporcional de apoyo electoral. El segundo principio es el de la gobernabilidad, el mismo pretende producir un Gobierno proactivo en el cual debe quedar clara la responsabilidad colectiva de las políticas. Y el tercer principio, denominado de rendimiento de cuentas individual, tiene como objetivo crear herramientas para que los votantes puedan castigar o recompensar el comportamiento de cada uno de los candidatos. ${ }^{2}$

En el sistema de representación mayoritaria es electo el candidato que obtiene mayor número de votos con relación a su contendiente o contendientes. En gran parte de los casos las elecciones que siguen este modelo exigen la mayoría absoluta de los votos, esto es la "mitad más uno". Si no existe en el primer turno la obtención de la mayoría absoluta de los votos válidos, habrá un segundo turno con los dos candidatos más votados. También existe el modelo de la mayoría relativa, en el cual es electo el candidato que obtiene el mayor número de sufragios sin necesidad de un segundo turno. Solamente el partido que obtiene la mayoría de los votos elige representantes y es por esto que este sistema es denominado mayoritario.

En el sistema de representación proporcional cada partido define internamente quiénes serán los candidatos que disputarán los escaños. Así, se cuentan los votos que cada partido obtuvo, atribuyéndose escaños a esos partidos, proporcionalmente al número de los votos. Los candidatos

2 John Carey, "Las virtudes del sistema electoral binominal", Revista de Ciencia Politica, vol. 26, núm. 1, Santiago, 2006, pp. 226-235. Arend Liphart, Modelos de democracia, Río de Janeiro, Civilização Brasileira, 2003. 
más votados de cada denominación partidaria serán aquellos que ocuparán el número de escaños atribuidos a su partido, siendo consecuentemente electos. En este tipo de sistema los grupos minoritarios participan del gobierno, correspondiéndose el número de representados y el número de representantes.

En el sistema de distritos electorales, para que haya mayor obediencia al principio de la proporcionalidad, se busca dividir el país en distritos electorales, que son regiones con aproximadamente la misma población. Cada distrito elegirá un diputado de su distrito, completando así los escaños en el parlamento y en las cámaras estatales o municipales. Este sistema es utilizado en muchos países. Algunos de ellos, sin embargo, como es el caso de Alemania, adoptan el sistema electoral mixto. Tal sistema supone que una parte de los diputados es electa por el voto de cada distrito, y los demás escaños son ocupados por los diputados electos por el sistema proporcional, los que pueden ser votados en todo el país. ${ }^{3}$

\section{EL SISTEMA ELECTORAL BINOMINAL EN CHILE: BASES CONCEPTUALES E IMPLICACIONES POLÍTICO-DEMOCRÁTICAS}

El sistema binominal es un sistema de elecciones populares destinado a la formación de un sistema bipartidista en torno a dos grandes partidos políticos o coaliciones. Dicho sistema es de particular interés para los fines del presente artículo por ser el imperante en Chile desde comienzos del decenio de $1980 .{ }^{4}$

Este sistema está basado en la elección de representantes según votaciones en divisiones electorales (como distritos y circunscripciones en el caso chileno), sin importar el resultado de las agrupaciones políticas en el ámbito nacional, eligiéndose en cada división dos miembros para

\footnotetext{
3 Arend Liphart, Las democracias contemporáneas, Buenos Aires, Ariel, 1998.

${ }^{4}$ Manuel Antonio Garretón, "El difícil reintento de un proyecto de país: la sociedad chilena a comienzos del siglo", en Roberto Bouzas [org.], Realidades nacionales comparadas/Argentina, Bolivia, Brasil, Chile, Paraguay, Uruguay, Buenos Aires, Altamira, 2002, pp. 245-300.
} 
la respectiva cámara. Conforme a esto último, las declaraciones de candidaturas a senadores o diputados que presenten los partidos políticos o los pactos electorales pueden incluir hasta dos candidatos por circunscripción senatorial o distrito según corresponda. Y en el caso de las candidaturas independientes, un candidato. ${ }^{5}$

Concluida la votación y resueltas las reclamaciones que tuvieran lugar, el Tribunal Calificador de Elecciones realiza la suma total de votos emitidos en favor de los candidatos de una misma lista, pacto o nómina. Tal resultado determinará los votos de la lista o nómina, procediendo a proclamar elegidos senadores o diputados a los dos candidatos de una misma lista, cuando ésta alcanzare el mayor número de sufragios y tuviere un total de votos que excediere el doble de los que alcanzare la lista o nómina que le siguiere en número de sufragios. ${ }^{6}$ En el caso que ninguna lista obtuviere los dos cargos, elegirá un cargo cada una de las listas o nóminas que obtengan las dos más altas mayorías de votos totales de lista o nómina, debiendo el Tribunal proclamar senadores o diputados elegidos a aquellos candidatos que, dentro de cada lista o nómina, hubieren obtenido las más altas mayorías. ${ }^{7}$

En Chile, el sistema binominal fue diseñado por el jurista y académico Jaime Guzmán, a pedido del general Augusto Pinochet — gobernante de facto entre 1973 y 1990. La Constitución Política de 1980 entrega la regulación del sistema electoral a una Ley orgánica constitucional, materias hoy reguladas por la Ley $\mathrm{N}^{\circ} 18.556$ sobre sistema de inscripciones electorales y servicio electoral de 1986 , y por la Ley $\mathrm{N}^{\circ} 18.700$ sobre votacio-

${ }^{5}$ Ley Orgánica Constitucional № 18.700 , Artículo $4^{\circ}$, incisos 1 y 5. Conviene agregar que la Constitución vigente en el país fue promulgada en 1980. Esta Constitución fue legitimada en un polémico referéndum nacional. Desde el retorno al sistema democrático han existido diversas tentativas de modificar o eventualmente sustituir su texto.

${ }^{6}$ Constitución Política de Chile, Artículos 107 y 109.

7 El Artículo 18 de la Constitución Política de Chile estipula un sistema electoral público, disponiendo en su inciso $2^{\circ}$ : "Una ley orgánica constitucional determinará su organización y funcionamiento, regulará la forma en que se realizarán los procesos electorales y plebiscitarios, en todo lo no previsto por esta Constitución y, garantizará siempre la plena igualdad entre los independientes y los miembros de partidos políticos tanto en la presentación de candidaturas como en su participación en los señalados procesos". 
nes populares y escrutinios, dictada por la Junta Militar en 1988. Esta última Ley rige la elección del Senado y de la Cámara de Diputados de la República, además de la de Presidente de la República. ${ }^{8}$

Es posible clasificar el sistema electoral binominal de Chile como minoritario empírico, puesto que otorga representación a la minoría, pero que no es proporcional, sino simplemente determinada por la norma legal. Los sistemas minoritarios empíricos son aquellos en que la representación de las minorías se determina conforme a un criterio arbitrario o meramente voluntarista. Éste consistiría en evitar la división tradicional de las fuerzas políticas chilenas en tres tercios (derecha, centro e izquierda) ya que con este sistema uno de los tercios vería disminuida su posibilidad de representación.

Obsérvese que debido a este sistema en muchas oportunidades el candidato con la segunda mayoría no es electo siendo reemplazado por uno con la tercera o, inclusive, la cuarta mayoría. De igual forma, diversas colectividades políticas de menor representatividad dicen ser excluidas del parlamento. Tal es el caso, por ejemplo, del Partido Comunista de Chile, organización político-electoral que ha logrado cifras cercanas a 5\% total de los votos, pero nunca ha conseguido un escaño desde 1990. Esto ha provocado fuertes críticas por parte de la izquierda extraparlamentaria, representada por el Juntos Podemos Más (comunistas y humanistas), y de los sectores socialdemócratas representados en la Concertación, que consideran a este sistema excluyente y poco democrático, a pesar que a esta última coalición también le es favorable el sistema.

Por otro lado, los representantes de la coalición de derecha, la así llamada Alianza por Chile, que también ha sido beneficiada por el sistema, plantean que este mecanismo permite alcanzar una mayor estabilidad política al promover la creación de dos bloques fuertes (oficialista y opositor), evitando de este modo una crisis política como la ocurrida durante el gobierno de la Unidad Popular de Salvador Allende en 1970. ${ }^{9}$

8 Hernán Molina Guaita, Instituciones politicas, Concepción, Universidad de Concepción, 1996.

9 Nótese que la formación de sistemas bipartidistas más o menos institucionalizados también acontece en otros países, entre ellos: Estados Unidos (demócratas y republi- 
Parece existir unanimidad en que el sistema binominal chileno ha favorecido a las dos mayores coaliciones del sistema político: la Concertación de Partidos por la Democracia y la Alianza por Chile. Carey pondera que el sistema binominal, tal cual funciona en Chile, "crea dos umbrales de voto fundamentales en los que las listas obtienen una mayor representación dentro de cada circunscripción". ${ }^{10} \mathrm{El}$ mismo autor verifica que los niveles precisos de dichos umbrales dependen de la distribución de los votos en todas las listas, pero la segunda lista más votada logrará un escaño siempre que obtenga más de la mitad de los votos obtenidos por la primera; $y$, a la inversa, la mejor situada sólo podrá conseguir los dos escaños si duplica el porcentaje de votos de la segunda lista. Lo anterior ha tenido como consecuencia que los sectores de la derecha han conseguido grandes ventajas, "ganando más de la mitad de los votos obtenidos por la Concertación (cruzando el primer umbral), pero no tanto como ésta — ni mucho menos doblando su porcentaje-en gran número de circunscripciones". ${ }^{11}$

Los beneficios de la Concertación, a partir del sistema electoral en cuestión, se obtienen de una forma más compleja, al cruzar el segundo umbral mencionado. Esto ocurre cuando ésta duplica el porcentaje de votos de la Alianza, aunque esta situación se presenta en un número de distritos relativamente escaso y con una victoria estrecha, malgastando muy pocos votos. En los distritos en los que la Concertación consigue "doblar", cosecha una ventaja electoral agregada similar a la obtenida por la derecha. Esta bonificación, tanto del conglomerado oficialista cuanto de la derecha, se produce a costa de todas las demás listas.

canos), España (populares y socialistas), Francia (gaullistas y socialistas), y Alemania (socialdemócratas y demócrata-cristianos).

${ }^{10}$ Carey, op. cit., p. 230.

${ }^{11}$ A pesar de que el sistema binominal sólo favorece a los dos grandes conglomerados políticos, han ocurrido casos excepcionales como en las elecciones parlamentarias de 2005, el Partido de Acción Regionalista, representado por la candidata a diputada Marta Isasi, logró quebrar el sistema binominal en el $2^{\circ}$ distrito de Iquique. De igual manera, en el Senado, el independiente Carlos Bianchi logró ser electo por la XII Región de Magallanes y de la Antártica Chilena. 
Desde 1990, el oficialismo ha propuesto en varias oportunidades la derogación del binominalismo. Estos intentos han naufragado debido a la completa oposición de la bancada de la Alianza, la cual ostentaba la mayoría del Parlamento o la mitad de éste, debido al binominalismo y a la presencia de senadores designados. El único paso importante ocurrió como parte de las reformas constitucionales del año 2005, cuando el sistema electoral fue transferido desde la Constitución a una Ley Orgánica, la que aún necesita de quórum cualificado para ser modificada.

A finales de diciembre de 2005, días después de las elecciones presidenciales de ese año, el gobierno de Ricardo Lagos envió a la Cámara de Diputados un proyecto de ley de carácter urgente para reformar el sistema binominal. Dicho proyecto constaba de enmiendas a la Constitución para eliminar el número fijo de diputados (120 en la actualidad). Asimismo, el proyecto comprometía al Congreso Nacional a buscar un nuevo sistema electoral en el periodo de un año. Este proyecto fue rechazado por la Alianza por Chile a través de la abstención de sus parlamentarios en la votación, argumentando que era un proyecto vacío y que no era correcto discutir el tema en tiempo electoral, ya que eventualmente podría ser utilizado por el gobierno como forma de apoyar la candidatura de Michelle Bachelet.

Luego de haber asumido la presidencia, Michelle Bachelet conformó una comisión especial para estudiar las modificaciones al sistema binominal. Esta comisión, compuesta por personas de diferentes partidos políticos - a excepción de la Alianza por Chile que prefirió automarginarse- fue liderada por el prestigiado académico chileno Edgardo Boeninger. Sin embargo, su propuesta fue rechazada por sectores tanto de oposición como de la propia coalición gobernante.

Los intentos de reforma serían retomados en abril de 2007, cuando el ministro José Antonio Viera-Gallo anunciara una propuesta con cambios menores al sistema electoral. Según la propuesta, al sistema electoral vigente se agregarían 20 diputados a la Cámara, los cuales corresponderían a los candidatos que estuviesen más cerca de ser electos diputados y dentro de los cuales se integrarían hasta cinco escaños a las coaliciones que 
hubiesen alcanzado un umbral de 5\% de los votos. Esta propuesta tampoco tuvo el apoyo necesario para su aprobación.

En síntesis, para los fines del presente artículo parece importante insistir y ponderar que el sistema binominal chileno termina provocando, entre otras, las siguientes implicaciones político-electorales:

- Las elecciones chilenas producen coaliciones fácilmente identificables por los votantes entes de las elecciones; que, en líneas generales, han puesto en práctica las políticas y programas con los que hicieron campaña para llegar al poder, y que han gobernado con eficiencia.

- El sistema binominal ha mejorado considerablemente la representación de las minorías que han querido y podido entrar en alianzas electorales amplias.

- Las elecciones legislativas chilenas también han proporcionado un foro para el desarrollo de una oposición electoral viable, así como un marco institucional en el que esta coalición puede operar.

- Las listas conceden a los votantes chilenos la oportunidad de recompensar o castigar, mediante una simple marca en la lista, la actuación en el poder o en una campaña de cada uno de los candidatos a parlamentarios.

- El reducido número de candidatos en cada una de las circunscripciones impide que las campañas se conviertan en cacofonías de propuestas individuales que podrían confundir más que informar a los votantes. El sistema de listas abiertas también les concede a los candidatos oportunidades e incentivos relativamente limitados para manifestar erróneamente sus preferencias de manera estratégica, lo cual constituye un problema que asuela a muchos otros sistemas electorales que pretenden combinar el voto por un individuo determinado con cierto margen de proporcionalidad.

Paralelamente, y como es de esperarse, existen muchas fuerzas políticas y sociales que abogan por una reforma electoral amplia, constructiva y realmente pluralista. Se sugiere que para conseguir una consolidación democrática realmente virtuosa será necesario superar este resquicio autoritario aún vigente en Chile. ${ }^{12}$

${ }^{12}$ Garretón, op. cit. 


\section{LA CONTIENDA ELECTORAL MUNICIPAL: ACTORES Y PROPUESTAS}

Poco después del fin de la dictadura comandada por el general Pinochet (1973-1990), las nuevas autoridades modificaron la institucionalidad para permitir la elección directa de alcaldes y concejales. Desde que se celebraron por primera vez, en 1992, las elecciones municipales se han convertido en un componente esencial de la democracia. Desde entonces, se celebran comicios municipales para la elección de concejales cada cuatro años. Ocurre lo mismo con las elecciones para alcaldes, de forma indirecta primero y directamente después.

Durante las cuatro elecciones municipales, celebradas entre 1992 y 2004, el porcentaje de alcaldes que busca la reelección no ha variado a través del tiempo y tampoco de acuerdo a la militancia partidista. Las tasas de reelección no se han modificado respecto a los mismos criterios. ${ }^{13}$ Las elecciones de 2008 surgen como una señal de modificación de esta tendencia.

\section{GobieRnos MUNicipales EN CHILE}

La comuna es la unidad básica de gobierno representativo en el sistema político chileno. Las comunas se agrupan en provincias y éstas a su vez en regiones. Cada comuna tiene su gobierno propio, compuesto por un alcalde y por un número variable de concejales. De acuerdo al artículo 107 de la Constitución, las municipalidades "son corporaciones autónomas de derecho público, con personalidad jurídica y patrimonio propio, cuya finalidad es satisfacer las necesidades de la comunidad local y asegurar su participación en el progreso económico, social y cultural de la comuna”. Si bien la Constitución establece algunos preceptos básicos que regulan el funcionamiento y atribuciones de los gobiernos municipales, una Ley Orgánica Constitucional de Municipalidades — Ley 18695 de

${ }^{13}$ Patricio Navia y Kenneth Bunker, "Elecciones municipales y reelección de alcaldes en Chile: 1992-2004", Serie en Foco: Política y Sociedad, Santiago, Expansiva, 2007. En http://www.expansivaudp.cl/en_foco/?categoria=PYS\&year= (fecha de consulta: 24 de noviembre, 2008). 
31 de marzo de 1988, modificada por última vez en 2006 - regula los detalles del funcionamiento de estas unidades comunales de administración y gobierno democrático. Las 346 comunas del país, agrupadas en 345 municipalidades, escogen democráticamente sus alcaldes y concejales en elecciones celebradas cada cuatro años. Las comunas con menos de 75 mil personas inscritas en el registro electoral escogen seis concejales. Las comunas con una cantidad de inscritos que fluctúa entre los 75 mil y los 150 mil tienen ocho concejales. Y las comunas con más de 150 mil inscritos escogen diez concejales.

Obsérvese que el número de comunas ha aumentado a través de los años. En 1992 el país tenía un total de 335, cantidad que aumentó a 342 en 1996, incluyendo la Antártica, que para efectos administrativos es parte de la municipalidad de Navarino. La cifra se mantuvo para las elecciones de 2000, en tanto que para las municipales de 2004 el número total de municipalidades alcanzó 345, el mismo número de las elecciones de 2008 .

\section{Relevancia de las Elecciones Municipales}

En un primer momento se podría pensar que las elecciones municipales, dado que ocurren en una delimitación geográfica y política muy localizada, no deberían entenderse como evaluaciones del electorado sobre la política nacional ni sobre el gobierno. Entretanto, siguiendo a Navia y Bunker, "la evidencia parece demostrar que, si bien hay importantes componentes locales en las contiendas municipales, éstas también dan cuenta de una especie de marea electoral producida por los efectos de los procesos políticos nacionales". ${ }^{14}$

La popularidad de los gobiernos chilenos parece estar directamente relacionada con el desempeño electoral de la coalición oficial en las contiendas municipales y, si bien, éste no redunda automáticamente en la obtención de alcaldías en el ámbito nacional, sí constituye una herramienta

${ }^{14}$ Loc. cit. 
de medición del éxito político de los distintos partidos y coaliciones. Un partido que obtiene una votación alta en las elecciones municipales, aunque obtenga menos alcaldes que otros, puede reclamar para sí un apoyo electoral superior al de otros partidos que, obteniendo más alcaldes, sumaron menos votos. Por eso, el porcentaje de votos logrados en una contienda municipal parece ser casi tan importante como el número de alcaldías que cada partido y coalición logra obtener.

En las cuatro elecciones municipales celebradas hasta hoy, la aprobación del desempeño del presidente está altamente correlacionada con la votación alcanzada por su coalición. De la misma forma, la votación que recibe la coalición opositora más importante, la Alianza por Chile, está positivamente correlacionada con los niveles de desaprobación del presidente concertacionista de turno.

En síntesis, hay poca variedad en la militancia del presidente de turno, pues todos han sido de la Concertación, en los niveles de aprobación presidencial y en la votación obtenida por las coaliciones en las contiendas municipales, pero la evidencia es clara respecto a que sí existe una correlación positiva entre los resultados electorales municipales en el ámbito nacional y los niveles de aprobación presidencial.

Michelle Bachelet EN LA Mitad DE SU GobieRnO: BREVE EVALUACióN CON BASE EN TENDENCIAS DE OPINIÓN PÚBLICA (MARZO DE 2006 A OCTUBRE DE 2008)

La presidenta Bachelet fue la gran triunfadora en las elecciones presidenciales de 2005, después de vencer, en segunda vuelta, al candidato de Renovación Nacional (centro-derecha) totalizando $45.96 \%$ de los votos. ${ }^{15}$ Bachelet asumió el cargo de presidenta de la República el día 11 de marzo

${ }^{15}$ Gaudichaud Franck, "A eleição de Michelle Bachelet, a transição e a democracia chilena: ruptura ou continuidade?", en Carlos Santander y Nelson Penteado [orgs.], Os processos eleitoriais na América Latina (2005-2006), Brasilia, LGE, 2008, pp. 263275 . 
de 2006. ${ }^{16} \mathrm{Y}$ desde entonces su gobierno ha sido monitoreado por una importante secuencia de encuestas de opinión pública realizadas por la empresa Adimark GFK. ${ }^{17}$ Aun reconociendo el escepticismo que algunos académicos recomiendan ante tales investigaciones, los resultados de las pesquisas sugieren que, entre marzo de 2006 y octubre de 2008, la aprobación a la gestión presidencial osciló entre un máximo de $63.1 \%$ (en abril de 2006) y un mínimo de $35.3 \%$ (en septiembre de 2007). Inversamente, la misma serie mensual sugiere que la desaprobación de la gestión gubernamental creció significativamente, oscilando entre el 8.2\% (en marzo de 2006) y un máximo de $46.17 \%$ (en agosto de 2008).

Conviene agregar que los datos proporcionados por la Encuesta también dan cuenta de la evaluación de la gestión en función de género, distribución de ingreso — según cuartiles de renta—, localización geográfica, esto es, región metropolitana de Santiago y regiones del interior del país, y adscripción/preferencias político-electorales de los encuestados.

En octubre de 2008, justo antes de los comicios municipales tratados en este trabajo, la misma fuente sugiere que la aprobación y desaprobación al gobierno de la presidenta Bachelet se situaba en $46.3 \%$ y $41.0 \%$ respectivamente, siendo que $6.7 \%$ manifestaron no aprobar ni reprobar, y $6.0 \%$ manifestó no saber y no respondió (véase Cuadro 1). Aunque una evaluación exhaustiva de los resultados mencionados excede los límites del presente artículo, es importante apreciar que el gobierno de la presidenta Bachelet tendría un mayor apoyo en el electorado femenino, entre los sectores más populares de la sociedad, en las regiones del interior del país y, obviamente, entre los simpatizantes de la Concertación. Y la desaprobación sería particularmente evidente entre los sectores más acaudalados de la sociedad y por los simpatizantes de la Alianza por Chile.

${ }^{16}$ Michelle Bachelet, "Programa de Governo (2006-2010)", Diplomacia, Estratégia Política, núm. 4, Brasilia, 2006, pp. 44-65.

${ }^{17}$ Se trata de la serie intitulada "Encuesta de evaluación de gestión del gobierno", publicada mensualmente por la prensa chilena y también disponible en Internet. La metodología consistió en un estudio cuantitativo, donde la muestra fue del tipo probabilístico, con selección aleatoria de hogares y de entrevistados. El universo fue compuesto por 


\section{Cuadro 1}

Evaluación de la gestión del gobierno chileno en octubre de 2008, según estudios de opinión pública (porcentajes*)

\begin{tabular}{|l|r|r|r|r|r|r|r|r|r|r|r|r|r|}
\hline & \multicolumn{3}{|c|}{ Género } & \multicolumn{3}{c|}{$\begin{array}{c}\text { Distribución de ingreso } \\
\text { (por cuartiles) }\end{array}$} & \multicolumn{2}{c|}{ Región geográfica } & \multicolumn{4}{c|}{ Preferencias político-electorales } & Total \\
& Hombre & Mujer & C1 & C2 & C3 & C4 & Santiago & Regiones & Concertación & $\begin{array}{c}\text { Juntos } \\
\text { Podemos }\end{array}$ & $\begin{array}{c}\text { Indepen- } \\
\text { dientes }\end{array}$ & $\begin{array}{c}\text { Alianza } \\
\text { por Chile }\end{array}$ & \\
\hline Aprueba & 44.2 & 48.4 & 42.2 & 41.3 & 40.5 & 50.8 & 42.0 & 49.2 & 72.8 & 55.7 & 37.8 & 31.1 & 46.3 \\
\hline Desaprueba & 45.6 & 36.6 & 51.0 & 47.9 & 44.1 & 36.3 & 45.7 & 37.8 & 18.8 & 36.0 & 43.0 & 63.1 & 41.0 \\
\hline
\end{tabular}

FUENTE: Adimark GFK, "Encuesta de Evaluación de Gestión del Gobierno/ Informe Mensual Octubre 2008", Santiago de Chile. En <http://www.adimark.cl/medios/ Evaluacion_gobierno_oct-08.pdf $>$ (fecha de consulta: 6 de diciembre, 2008).

* La diferencia para completar $100 \%$ corresponde a la sumatoria de las respuestas "No aprueba, ni desaprueba" y "No sabe, no contesta".

La tendencia fundamentalmente declinante en el apoyo de la opinión pública ante la gestión de Bachelet es, naturalmente, preocupante para el gobierno. Es altamente probable que los datos de tales investigaciones debiliten su capacidad de acción política, dadas las dificultades que ha tenido hasta ahora para empujar su agenda. Muchos analistas políticos y sociales chilenos vinculan los cuestionamientos de la gestión de Bachelet a las grandes dificultades provocadas en el transporte público por el programa denominado Transantiago. ${ }^{18}$

los hogares que disponen de teléfono en las principales ciudades del país. La aplicación fue realizada a través de entrevistas telefónicas. El error se estima en $+/-3 \%$. El grupo objetivo estuvo compuesto por hombres y mujeres, mayores de 18 años, residentes en las 17 principales ciudades de Chile. Los datos fueron ponderados por ciudad, sexo, según datos del Censo 2002.

${ }^{18}$ Transantiago es un proyecto que busca mejorar la cobertura del transporte público de Santiago disminuyendo el número de transbordos, bajando los tiempos de espera y aumentando la oferta de recorridos. Sin embargo, la implantación del Transantiago creó varios problemas, develando deficiencias y errores tanto de planificación como de implantación del proyecto. Ello creó una virtual crisis nacional, implicando un fuerte desgaste de la imagen y popularidad del gobierno de la presidenta, lo que explica que la aprobación a la conducción gubernamental en la capital sea menor que en las demás regiones. 
Sin embargo, concentrar excesivamente en el Transantiago los orígenes de la desaprobación al gobierno de Bachelet sería desconocer que, a pesar de que su apoyo regional es mayor, está lejos de ser satisfactorio, sobre todo a la luz del buen desempeño económico promedio de las regiones..$^{19}$ Esta realidad deja entrever, pues, una crítica a la conducción gubernamental que sobrepasa a la que se origina en la del transporte público de Santiago. Todo indica que, en particular, la delincuencia, algunas acusaciones de corrupción y las dificultades gubernamentales para plantear una agenda coherente en el campo social - especialmente en los sistemas públicos de educación y salud - han tenido un impacto mayor en la evaluación del gobierno.

Es importante destacar que, pese a la negativa evaluación de su administración, las cualidades personales de la presidenta siguen intactas. Esto sugiere que hay una oportunidad para que La Moneda revierta esta deficiente apreciación ciudadana, rediseñando la gestión del gobierno, dándole un mayor sustento político y lograr la unidad del gabinete en torno al programa del mismo.

Muchos analistas políticos chilenos y los propios datos recolectados por los autores del presente estudio confirman que la declinante evaluación gubernamental ha afectado a la Concertación como coalición política. Y ello no dejó de estar presente en los resultados de las elecciones municipales. Entretanto, es importante recalcar que los niveles de aprobación son bajos también para la gestión y el desempeño de la oposición política, en su función de fiscalizar constructivamente las acciones de gobierno. En consecuencia, la pesquisa de opinión pública sugiere que la alta desafección ciudadana hacia la política no termina favoreciendo del todo a la oposición. Con todo, se ha configurado un cuadro en el que la Concertación, por primera vez, no tiene ya una ventaja evidente sobre la Alianza.

${ }^{19}$ Ricardo French-Davis, "Chile: entre el neoliberalismo y el crecimiento con equidad", en Bouzas, op. cit., pp. 219-243. Flavio Pinheiro, "Chile: um país em movimento", en Maria Lima e Marcelo Coutinho [orgs.], A Agenda Sul-Americana: Mudanças e Desafios no Início do Século XXI, Brasilia, Funag, 2007, pp. 137-173. 


\section{LAS ElECCIONES MuNICIPALES DE OCTUBRE DE 2008: ANÁLISIS Y TENDENCIAS}

El voto es obligatorio en Chile únicamente para los ciudadanos que, voluntariamente, decidieron inscribirse en el registro electoral correspondiente. ${ }^{20}$ En consecuencia, en las elecciones municipales abordadas en este trabajo fueron habilitados 8110265 ciudadanos para votar. Concurrieron 1231 candidatos a alcalde para 345 comunas, 272 alcaldes intentaron la reelección. De este número, 66 buscaron reelegirse por una tercera vez, 41 por la cuarta vez y 48 por la quinta. Esto quiere decir que solamente $20 \%$ de los candidatos representaron nuevas opciones. La posibilidad de reelección indefinida termina siendo un obstáculo para una recomendable renovación política, sobre todo en un escenario en que no existen mecanismos claros de rendición de cuentas, que terminan, en gran parte de los casos, transformándose en un recurso más publicitario. Concomitantemente, se presentaron 9486 candidatos a concejales para 2160 cupos.

De modo general, la mayoría de los observadores de los comicios consideraron que los resultados de octubre de 2008 no fueron positivos para las fuerzas políticas agrupadas en torno al proyecto de la Concertación. En efecto, la oposición de centroderecha obtuvo $41 \%$ de los votos para las alcaldías contra $39 \%$ de la Concertación, ganando ocho de las 14 capitales regionales en disputa. Este resultado significó la primera derrota en el ámbito nacional para la Concertación, desde el fin de la dictadura del general Augusto Pinochet en 1990 (véase Anexo 1).

En todo caso, esta victoria no fue absolutamente inequívoca. Así, en la elección para concejales, que se eligen separadamente de los alcaldes, la Concertación obtuvo $45 \%$ de los votos, contra $36 \%$ de la Alianza. Este dato debe ser complementado con la información de que hubo, aproximadamente, $10 \%$ más electores que votaron por alcaldes.

${ }^{20}$ El voto no es obligatorio para aquellos ciudadanos que, por diferentes motivaciones, no consideran prudente, necesario o apropiado inscribirse en el registro electoral correspondiente. Esto es particularmente preocupante en el caso de los jóvenes chilenos, muchos de los cuales no demuestran interés en someterse a tales regulaciones lo que naturalmente es alarmante y sugestivo. 
A pesar de que, como ya se ha analizado en la primera parte del presente artículo, el sistema electoral chileno divide al país en distritos binominales, consolidando así un sistema de dos coaliciones y castigando una tercera parte, un nuevo conglomerado, constituido mayoritariamente por ex miembros del Partido Demócrata Cristiano (PDC) y reunidos en el pacto Por un Chile Limpio, obtuvo $7.57 \%$ de los votos en la elección para concejales. A este hecho hay que agregar los votos obtenidos en la misma elección por el pacto Juntos Podemos Más, de izquierda no concertacionista, que obtuvo $9.08 \%$ del total de los sufragios (véanse Anexos 1 y 2).

Antes de concluir el presente acápite parece importante agregar breves comentarios sobre dos tópicos altamente relevantes y significativos: la transparencia y legitimidad del proceso electoral, por un lado, y la participación de candidaturas femeninas (o enfoque de género), por el otro.

Con relación al primer tópico, en general las elecciones ocurrieron sin mayores contratiempos o denuncias de fraude o corrupción, salvo algunos casos aislados, como aquel ocurrido en la comuna de Cholchol (región de la Araucanía), donde la elección tuvo que repetirse, en algunas mesas, el 18 de enero de 2009. Sin embargo, la nueva votación no alteró la mayoría alcanzada por Violeta Cea Villalobos de la Unión Democrática Independiente (UDI) en la primera elección.

La alcaldesa de la comuna de Pelluhue (región del Maule), María Luz Reyes, del partido Renovación Nacional (RN), resultó reelecta con $41 \%$ de los votos, pero fue removida de su cargo por el Tribunal Electoral Regional, tras ser acusada de cohecho, quedando inhabilitada para ejercer cualquier cargo público por un periodo de cinco años. ${ }^{21}$ El Tribunal Electoral Regional decidió que el alcalde saldría de entre los concejales electos, que ellos mismos votarían. Sin embargo, luego de varios empates, tres concejales pro Concertación se negaron a efectuar un desempate por estar en desacuerdo con el procedimiento. Luego de varias ausencias al concejo municipal, los tres concejales fueron imputados por la justicia

21 "Remueven a la alcadesa reelecta de Pelluhue", La Tercera, Santiago de Chile, 2.11.2008. En www.latercera.cl (fecha de consulta: 15 de septiembre, 2009). 
por desacato, quedando con arraigo nacional y firma semanal, mientras dura la investigación. La comuna continúa sin alcalde.

En la comuna de Sierra Gorda (región de Antofagasta) el Tribunal Electoral decidió anular las elecciones de alcalde y concejales debido a irregularidades en el padrón electoral de la comuna. Una nueva elección, llevada a cabo el 14 de junio de 2009, también fue anulada, por los mismos motivos. Finalmente, en julio de 2009, el Tribunal Calificador de Elecciones terminó ratificando los resultados, con lo que el candidato José Guerrero resultó electo alcalde.

Con relación a la cuestión de la participación de candidaturas femeninas es evidente que no fueron buenos los resultados de las elecciones municipales para las mujeres. En total aumentaron de 41 a 43 alcaldesas (de $11.9 \%$ a $12.5 \%$ ), aunque las candidaturas habían aumentado de 203 a 214 (16.3\% a 17.4\%). Estos porcentajes están lejos de la participación femenina en el electorado: $52.5 \%$ de los inscritos y de la votación de mujeres que, en esta oportunidad, superó a los varones por 454697 votos $(53.3 \%$ de los votos válidamente emitidos).

Independientemente de su afiliación política, las alcaldesas aumentaron sólo en dos, pero la mayor ganancia estuvo del lado de la Alianza por Chile, a cuyas filas pertenece $62.8 \%$ de las nuevas alcaldesas. Se suman una alcaldesa del pacto Chile Limpio, del pacto Juntos Podemos, y cuatro independientes. Tres regiones tienen ahora seis mujeres alcaldesas (Valparaíso, Maule y Metropolitana), pero Arica no tienen ninguna.

En el caso de la elección de regidores o concejales, en estas elecciones los partidos concertacionistas presentaron más mujeres candidatas - sumadas las dos listas Concertación Democrática y Concertación Progresista - alcanzando a 1057 sobre un total de 5105 candidaturas. Superaron por primera vez $25 \%$ de las candidaturas (25.7\%). También las mujeres votaron más por candidatos de la Concertación, con 224948 adicionales, pero no encontraron candidaturas de mujeres suficientes que recogieran su voluntad mayoritaria. En realidad, sólo 253 mujeres resultaron electas, es decir, $23.9 \%$ de las candidatas, las que recogieron un porcentaje elevado de votación femenina. 
El total de concejalas elegidas en el país fue 493, perteneciendo 51.3\% a la Concertación. Aumentaron en concejalas el pacto Juntos Podemos (16), y el nuevo Pacto Chile Limpio (26) eligió un número importante también. Consideradas las mujeres en su conjunto las concejalas aumentaron de 444 a 493, es decir subieron de 20.9\% a 23\%, 49 concejalas más en el país. La Región Metropolitana tiene el mayor número de mujeres concejalas.

Si bien mantuvieron las concejalas de la Concertación su participación entre el total de mujeres concejalas, al superar 50\%, esta elección contó con más del doble de candidaturas para obtener casi el mismo rendimiento, con un desgaste de proporciones porque 804 candidatas mujeres perdieron, al haber realizado un importante trabajo de campaña, con gran esfuerzo y gasto de recursos, arriesgando su capital político al interior de los propios partidos, que las considerarán "perdedoras" en su posible carrera política futura.

CONSIDERACIONES FINALES: IMPLICACIONES CON VISTAS A LOS COMICIOS PRESIDENCIALES DE 2009

Las elecciones municipales chilenas de octubre de 2008 deben ser apreciadas - primero y prioritariamente - como un fenómeno político eminentemente local. En otras palabras, las elecciones en cada una de las casi 350 comunas del país responden a las expectativas, necesidades, preferencias y visiones de los problemas parroquiales. En tal sentido, vale adelantar que se trató de un ejemplar ejercicio de democracia electoral en la menor unidad político-administrativa existente en Chile. Igualmente, debe destacarse que los resultados fueron reconocidos por la gran mayoría de los actores políticos y sociales relevantes, tanto de la coalición gobernante, como de la oposición y de la sociedad civil, en general. La primera ponderación fundamental que cabe citar, entonces, es que la democracia chilena dio un importante paso al frente en su proceso de consolidación. Todo ello con valiosas y virtuosas consecuencias domésticas y regionales. 
Es evidente que los comicios municipales implicaron un importante aviso para las fuerzas políticas agrupadas en torno a la Concertación de Partidos por la Democracia. Recuérdese que — desde 1988 - los partidos que forman parte de la Concertación nunca habían sido derrotados en procesos electorales de porte nacional o municipal. Después de casi veinte años de gobiernos - Aylwin, Frei, Lagos y Bachelet—, la alianza de centro-izquierda chilena tiene un gran desafío político-electoral e ideológico-programático delante de sí. Las primeras reacciones de los dirigentes de los diferentes partidos de la Concertación - especialmente en el caso del Partido Demócrata Cristiano - apuntan a una autocrítica firme y constructiva. Algunos analistas sugieren que la Concertación debería abrir espacios de diálogo y eventualmente aceptar la incorporación de otras fuerzas de izquierda, tal es el caso de los comunistas, de los humanistas y de algunos independientes. Una renovación de los cuadros dirigentes, muchos de ellos conocidos - y desgastados- es una alternativa posible y necesaria. Difícilmente la Concertación continuará en La Moneda con dirigentes veteranos - tales como Ricardo Lagos, Eduardo Frei o José Miguel Insulza — nos comentaron muchos entrevistados en la época de la investigación de campo de este artículo. Aunque no fue una derrota avasalladora, la Concertación y la propia presidenta Michelle Bachelet sufrieron un duro golpe político-electoral. Y las tendencias con vistas a los próximos comicios presidenciales oscilan entre la incertidumbre y el pesimismo.

En el caso de las fuerzas políticas de centro-derecha, agrupadas en la Alianza por Chile, los resultados de las elecciones municipales son sumamente favorables y promisorios. Después de muchos años de virtual ostracismo político-electoral, los partidarios de Renovación Nacional y de la Unión Demócrata Independiente lograron un expresivo respaldo popular en casi todas las regiones del país. La mayoría de los analistas políticos, bien como las encuestas de opinión publicadas en los dos últimos meses de 2008, sugieren que los excelentes resultados en el ámbito local abren significativas perspectivas de triunfo, en el plano presidencial en 2009, sobre todo para el virtual candidato Sebastián Piñera Echenique. 
Obsérvese que la victoria de Pablo Antonio Zalaquett Said —candidato de la Unión Demócrata Independiente - en la Alcaldía de Santiago, una de las más emblemáticas de todo Chile, es particularmente relevante, simbólica y sintomática para la centro-derecha. Aun reconociendo que, dada la organización política del gran Santiago en 26 comunas diferentes, el volumen de votos específicos de la Alcaldía de Santiago no es tan significativo. Sin embargo, el peso ideológico-simbólico de una de las más tradicionales entidades político-administrativas locales chilenas excede, y mucho, la votación estrictamente municipal. En otras palabras, Santiago también se erigió en un modelo para otras corporaciones municipales del país, y del exterior. ${ }^{22}$

También conviene tomar nota de la expresiva votación lograda por fuerzas políticas emergentes, Juntos Podemos Más, regionalistas, especialmente en el norte chileno, e independientes. Las perspectivas de estas fuerzas políticas en el próximo proceso presidencial son muy reducidas. De modo general se trata de militantes de izquierda que no forman parte de la Concertación (comunistas, humanistas). Muchos de ellos podrán votar por candidatos de la Concertación en la hipótesis de acuerdos y convergencias. Difícilmente una candidatura independiente podrá quebrar la dialéctica Concertación-Alianza por Chile, a menos que el propio sistema binominal sea radicalmente modificado o sustituido por otro más pluralista y democrático.

${ }^{22}$ Actualmente seis de las diez más emblemáticas municipalidades, comunas o prefecturas latinoamericanas son gobernadas por alcaldes de partidos de centro-derecha: Gilberto Kassab en São Paulo, Óscar Luis Castañeda Lossio en Lima, Pablo Zalaquett en Santiago, Mauricio Macri en Buenos Aires, Adalberto Madero en Monterrey, y Antonio José Ledesma en Caracas. Paralelamente dos ciudades son gobernadas por partidarios de centro-izquierda, Marcelo Luis Ebrard Casaubón en ciudad de México y Samuel Gustavo Moreno Rojas en Bogotá, y otras dos por simpatizantes de partidos de centro, Eduardo da Costa Paes en Río de Janeiro y João Enrique Carneiro en Salvador de Bahía. Aparentemente las victorias en comicios electorales municipales están contribuyendo de forma altamente significativa en la recomposición de la derecha latinoamericana, lo que también está provocando consecuencias en el nivel presidencial o nacional. 
Por otro lado, es necesario registrar la alta y creciente apatía políticoelectoral de importantes segmentos de la sociedad chilena. Apreciaciones, comentarios y percepciones registradas por nosotros en la etapa de búsqueda de datos y trabajo de campo sugieren, y confirman, la existencia preocupante de una desafección política en el país. Quizá el segmento más escéptico sea el de los jóvenes, quiere decir, las personas de ambos sexos entre 14 y 30 años de edad. Dicho fenómeno también ha sido confirmado en otros países de la región. Sin embargo, en Chile parece ser particularmente agudo, lo que implica un importante desafío para toda la clase política del país, vigorosamente cuestionada por la gran mayoría de los jóvenes escuchados.

En suma, las elecciones municipales chilenas se erigieron en una positiva demostración de madurez cívica y ciudadana. Aun reconociendo que estos comicios deben ser analizados prioritariamente en el sentido local/parroquial, no parece incorrecto verificar que los resultados agregados generan importantes consecuencias para el futuro político del país en conjunto, especialmente en el contexto de un nuevo proceso electoral presidencial y parlamentario previsto para 2009 (y con eventual segundo turno en enero de 2010). Al atenerse a los resultados globales se percibe un resultado favorable para la coalición de centro-derecha, que ahora presenta condiciones creíbles y plausibles para reconquistar, por la vía electoral, la presidencia de la República. Para la Concertación de Partidos por la Democracia los resultados deberán ser interpretados cuidadosamente, especialmente en términos programáticos y de liderazgo. La propia noción de democracia utilizada por los gobiernos de Lagos y Bachelet, muy semejante a la planteada por la social-democracia alemana y por el socialismo español, deberá ser repensada y eventualmente sustituida por una verdadera concepción de democracia de ciudadanía. Los próximos meses serán muy importantes para la democracia chilena y latinoamericana, en general. La ola de gobiernos de centro-izquierda en Sudamérica está llegando a su máximo posible. Y las aparentemente ineluctables victorias presidenciales de la centro-derecha latinoamericana estarán íntimamente vinculadas a los positivos resultados cose- 
chados en comicios locales/municipales como los chilenos de octubre de 2008 .

\section{PoSDATA DE SEPTIEMBRE DE 2009}

Según una reciente encuesta de opinión, ${ }^{23}$ la presidenta Bachelet mantiene en julio de 2009 el alto nivel de aprobación alcanzado en los últimos meses, con una cifra de $73 \%$ de aprobación a su gestión. Sin embargo, el gobierno retrocede ocho puntos en el mismo mes, para marcar 57\% de aprobación. Posiblemente las causas de este retroceso están relacionadas con el impacto de la crisis económica mundial, mas la figura de la presidenta resulta indemne.

La mejoría más notoria del gobierno se da respecto al Transantiago, sistema respecto al cual se logró en el mes de julio un acuerdo entre el gobierno y la oposición para su financiamiento. La percepción respecto al Transantiago mejora, muy marcadamente en Santiago, para situarse en el mejor nivel que hayamos registrado sobre este controvertido sistema (32\%), desde su lanzamiento en 2007.

Otra área en que el gobierno ve mejorar su evaluación en julio es en la educación, que en el mes anterior había sido fuertemente castigada por los numerosos conflictos con estudiantes y profesores que paralizaron gran parte de la educación pública, con tomas de colegios y violencia callejera.

Según la encuesta ya mencionada, con la mejora del Transantiago, las áreas más críticas del gobierno, a distancia, son la corrupción en los organismos del Estado (18\% de aprobación, $70 \%$ de rechazo) y el control de la delincuencia ( $14 \%$ de aprobación, $80 \%$ de rechazo).

En relación a la evaluación del desempeño del Senado y de la Cámara de Diputados los resultados no son halagüeños para estas instituciones, que muestran niveles de aprobación muy reducidos (24\% para el Senado, $21 \%$ para la Cámara) y altos niveles de rechazo ( $57 \%$ el Senado,

${ }^{23}$ Véase www.adimark.com.cl (fecha de consulta: 27 de agosto, 2009). 
65\% la Cámara de Diputados). Estos sorprendentes niveles de desafección respecto a ambas ramas del Congreso Nacional son muy similares a lo que se obtiene para las coaliciones políticas.

Las coaliciones políticas tradicionales se ven afectadas negativamente, especialmente la Concertación, cuyo nivel de identificación cruza hacia la barrera de $20 \%$ (logra $19 \%$ en julio) y es superada por la Alianza ( $21 \%$ de identificación). Es probable que el conflictivo proceso de discusión de escaños para las elecciones parlamentarias esté marcando un punto bajo en la imagen de partidos y coaliciones.

Recibido: 19 de marzo, 2009. Aceptado: 17 de septiembre, 2009. 


\section{AneXos}

\section{Anexo 1: Resultado de la votación para Alcaldes}

\begin{tabular}{|c|c|c|c|c|}
\hline \multicolumn{5}{|c|}{ País } \\
\hline Lista/Pacto & Votos & $\begin{array}{c}\text { Porcentaje } \\
(\%)\end{array}$ & Candidatos & Electos \\
\hline Por un Chile Limpio & 249237 & 4.00 & 103 & 7 \\
\hline La Fuerza del Norte & 24182 & 0.38 & 4 & 1 \\
\hline Concertación Democrática & 1787271 & 28.71 & 227 & 99 \\
\hline Juntos Podemos Más & 396388 & 6.36 & 191 & 7 \\
\hline Alianza & 2524989 & 40.56 & 340 & 142 \\
\hline Concertación Progresista & 607159 & 9.75 & 102 & 47 \\
\hline Independientes (Fuera de Pacto) & 635118 & 10.20 & 264 & 40 \\
\hline Válidamente emitidos & 6224344 & & 1.231 & 343 \\
\hline
\end{tabular}

\begin{tabular}{|c|c|c|c|c|c|}
\hline Partido & $\begin{array}{c}\text { Sigla } \\
\text { Partido }\end{array}$ & Votos & $\begin{array}{c}\text { Porcentaje } \\
(\%)\end{array}$ & Candidatos & Electos \\
\hline Partido Regionalista de los Independientes & PRI & 54756 & 0,87 & 37 & 1 \\
\hline Independientes Lista A & ILA & 194481 & 3.12 & 66 & 6 \\
\hline Fuerza País & FP & 1141 & 0.01 & 1 & 0 \\
\hline Independientes Lista B & ILB & 23041 & 0.37 & 3 & 1 \\
\hline Partido Demócrata Cristiano & PDC & 1121574 & 18.01 & 136 & 58 \\
\hline Partido Socialista de Chile & PS & 579527 & 9.31 & 72 & 29 \\
\hline Independientes Lista C & ILC & 86170 & 1.38 & 19 & 12 \\
\hline Partido Comunista de Chile & $\mathrm{PCCH}$ & 155634 & 2.50 & 76 & 4 \\
\hline Partido Humanista & $\mathrm{PH}$ & 84130 & 1.35 & 30 & 1 \\
\hline Independientes Lista D & ILD & 156624 & 2.51 & 85 & 2 \\
\hline Renovación Nacional & $\mathrm{RN}$ & 822136 & 13.20 & 121 & 54 \\
\hline Unión Demócrata Independiente & UDI & 1244158 & 19.98 & 129 & 57 \\
\hline Independientes Lista E & ILE & 458695 & 7.36 & 90 & 31 \\
\hline Partido por la Democracia & PPD & 433739 & 6.96 & 65 & 35 \\
\hline Partido Radical Socialdemócrata & PRSD & 149967 & 2.40 & 28 & 11 \\
\hline Independientes Lista F & ILF & 23453 & 0.37 & 9 & 1 \\
\hline Independientes (Fuera de Pacto) & IND & 635118 & 10.20 & 264 & 40 \\
\hline Válidamente emitidos & & 6224344 & & 1231 & 343 \\
\hline
\end{tabular}

FuENTE: Ministerio del Interior de Chile, "Elecciones Municipales 2008”, 2008. En http://www.elecciones.gob.cl/ (fecha de consulta: 15 de diciembre, 2008). 
Anexo 2: Resultado de la votación para Concejales

\begin{tabular}{|c|c|c|c|c|}
\hline \multicolumn{5}{|c|}{ País } \\
\hline Lista/Pacto & Votos & $\begin{array}{c}\text { Porcentaje } \\
(\%)\end{array}$ & Candidatos & Electos \\
\hline Por un Chile Limpio & 421799 & 7.57 & 1429 & 117 \\
\hline La Fuerza del Norte & 27384 & 0.49 & 37 & 7 \\
\hline Concertación Democrática & 1554379 & 27.90 & 2092 & 673 \\
\hline Juntos Podemos Más & 506176 & 9.08 & 1589 & 80 \\
\hline Alianza & 2005153 & 35.99 & 2123 & 863 \\
\hline Concertación Progresista & 966183 & 17.34 & 2013 & 391 \\
\hline Independientes (Fuera de Pacto) & 88925 & 1.59 & 203 & 12 \\
\hline Válidamente emitidos & 5569999 & & 9486 & 2143 \\
\hline
\end{tabular}

\begin{tabular}{|c|c|c|c|c|c|}
\hline Partido & $\begin{array}{c}\text { Sigla } \\
\text { Partido }\end{array}$ & Votos & $\begin{array}{c}\text { Porcentaje } \\
(\%)\end{array}$ & Candidatos & Electos \\
\hline Partido Regionalista de los Independientes & PRI & 206399 & 3.70 & 639 & 64 \\
\hline Partido Ecologista & $\mathrm{PE}$ & 3819 & 0.06 & 11 & 0 \\
\hline Independientes Lista A & ILA & 211581 & 3.79 & 779 & 53 \\
\hline Fuerza País & $\mathrm{FP}$ & 1347 & 0.02 & 5 & 1 \\
\hline Independientes Lista B & ILB & 26037 & 0.46 & 32 & 6 \\
\hline Partido Demócrata Cristiano & PDC & 778766 & 13.98 & 887 & 343 \\
\hline Partido Socialista de Chile & PS & 622552 & 11.17 & 832 & 250 \\
\hline Independientes Lista C & ILC & 153061 & 2.74 & 373 & 80 \\
\hline Partido Comunista de Chile & $\mathrm{PCCH}$ & 277895 & 4.98 & 560 & 46 \\
\hline Partido Humanista & $\mathrm{PH}$ & 104715 & 1.87 & 417 & 13 \\
\hline Partido Izquierda Cristiana de Chile & $\mathrm{IC}$ & 2176 & 0.03 & 10 & 0 \\
\hline Independientes Lista D & ILD & 121390 & 2.17 & 602 & 21 \\
\hline Renovación Nacional & RN & 897617 & 16.11 & 834 & 388 \\
\hline Unión Demócrata Independiente & UDI & 840929 & 15.09 & 864 & 351 \\
\hline Independientes Lista E & ILE & 266607 & 4.78 & 425 & 124 \\
\hline Partido por la Democracia & PPD & 475665 & 8.53 & 678 & 195 \\
\hline Partido Radical Socialdemócrata & PRSD & 289121 & 5.19 & 713 & 113 \\
\hline Independientes Lista F & ILF & 201397 & 3.61 & 622 & 83 \\
\hline Independientes (Fuera de Pacto) & IND & 88925 & 1.59 & 203 & 12 \\
\hline Validamente emitidos & & 5569999 & & 9486 & 2143 \\
\hline
\end{tabular}

FuENTE: Ministerio del Interior de Chile, "Elecciones Municipales 2008", 2008. En http://www.elecciones.gob.cl/ (fecha de consulta: 15 de diciembre, 2008). 